\title{
USING A NEW WATER SENSING DEVICE TO DESIGN A NOVEL INTERACTIVE INSTALLATION FOR PRACTICING CONCENTRATION TO OBTAIN FLOW EXPERIENCES
}

\author{
Chao-Ming Wang ${ }^{* 1} \bowtie$, Mei-Yi Lai 2 四 \\ ${ }^{* 1,2}$ Department of Digital Media Design, National Yunlin University of Science \& Technology, Douliu \\ City, Yunlin County 64002, Taiwan, ROC
}

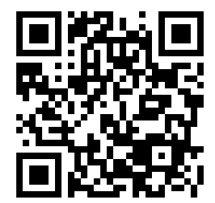

DOI: https://doi.org/10.29121/ijetmr.v8.i2.2021.873

Article Citation: Chao-Ming Wang, and Mei-Yi Lai. (2021). USING A NEW WATER SENSING DEVICE TO DESIGN A NOVEL INTERACTIVE INSTALLATION FOR PRACTICING CONCENTRATION TO OBTAIN FLOW EXPERIENCES. International Journal of Engineering Technologies and Management Research, 8(2), 46-69.

https://doi.org/10.29121/ijetmr.v8 .i2.2021.873

Published Date: 20 February 2021

Keywords:

Interactive Installation

Flow Experience

Sensors

Human-Computer Interaction

\begin{abstract}
Many interactive systems for conveying messages have been created recently, while the concept of flow experience that enhances the efficacy of people's activities via self-concentration has long been proposed. A novel interactive installation system is designed for a participant to practice concentration to obtain flow experiences. Precise water pouring into the system is adopted as the interactive process for practicing mind concentration. Persistent concentration and precise hand control are required to complete the watering process, and a water sensing device is designed to decide whether the watering action is successful. The system was evaluated by questionnaire surveys and expert interviews, revealing the following findings that prove the effectiveness of the proposed system: 1) the man-machine interaction provided by the system is innovative and interesting; 2) the immediate feedbacks of the system help a participant concentrate in mind; 3 ) the interactive watering process allows the participant to obtain the flow experience.
\end{abstract}

\section{INTRODUCTION}

\subsection{BACKGROUND AND MOTIVATION}

With the advance of technology, people are getting more and more familiar with the digital life - a way of living with digital technology. It is aimed in this study, by combining the interaction technology and mind control, to explore a new way of performing self-cultivation, one of the issues to which lots of people pay attention nowadays. "Interaction" is the way a person communicates with a technological device, and mutual influences occur between the person and the device in an interactive process. The purpose of creating an interactive device is to express the creator' idea and build communication with the participant via the device [1].

In addition, to get rid of worries about the details of the daily life, the concept of "Zen" has gradually become one of the natural ways for busy people to relieve pressures, to seek true self, and to conduct self-cultivation. In 2004, an experimental report about Zen meditation and neuroscience indicated that the psychological process of concentration is trainable [2]. Many western scholars thought that Zen, though often regarded as a kind of mysticism, is a transcendent ideology existing in the universe; and through this kind of thought, Zen was often applied in the field of 
human-machine interaction [3]. Somehow similar to Zen, the concept of "flow experience" proposed by Csikszentmihalyi refers to a person's involvement in a tranquil activity with a clear goal in mind [4]. He/she receives feedbacks through self-control and self-concentration, and has mental pleasure after finishing the activity.

In this study, it is desired to construct a system which introduces the interaction technology into the practice of concentration, with the expectation that people can adjust their concentration and feeling in mind while interacting with the system. Furthermore, by pacing themselves through such a mental process via the use of the system, it is hoped that they can easily regain their attention on things or tasks in concern. It is also desired in this study to use the constructed interactive system, which is based on the concentration concept, to investigate the relationship between the flow experience and the interaction technology, expecting the concentration-arousing interaction process offered by the proposed system to be helpful to the participant to obtain flow experiences. To accomplish this aim, the following research stages were followed in this study:

1) literature review - reviewing academic literatures about Zen and flow experiences as well as examples of related case studies to set up the ideas for designing the desirable interactive system;

2) Prototype Construction - constructing accordingly a prototype system, named "Zen-Drop," which is equipped with a new water sensing device designed for use in the system;

3) Field Experiment - carrying out a field experiment to invite user to experience the effectiveness of the proposed "Zen-Drop" system for practicing concentration in mind; and

4) System Evaluation - conducting questionnaire surveys and expert interviews by designing questions according to the Csikszentmihalyi's model [4] to evaluate whether the proposed system is helpful to improve the participant's capability of self-concentration to obtain the flow experience.

\subsection{LITERATURE REVIEW}

\subsubsection{FLOW EXPERIENCE}

The term "flow" means a state of mind with happiness in the human life [4], and the concept "flow experience" refers to a person's involvement in a tranquil activity which bring him/her pleasure after finishing the activity, no matter whether he/she has a deep feeling about the activity process or not. The flow experience has a close relationship with religion since it emphasizes self-adjustment and mental training to achieve self-growth. The term "flow experience" has other equivalents, such as "smooth experience" or "optimal experience." Its primary feature is sense of control. As reported by Csikszentmihalyi and other researchers [4], [5], [6], people have flow experiences under seven situations as described in Table 1. In addition, Chen et al. [1] categorized the flow experiences into three aspects: "condition," "feeling," and "result," which are also included in Table 1 and will be used as the assessment criteria of further discussions in this paper.

Table 1: A list of situations under which people have flow experiences.

\begin{tabular}{|c|c|}
\hline Aspect & Situation and explanation \\
\hline \multirow{3}{*}{ Condition } & Great inner clarity - knowing what needs to be done and how well we are doing. \\
\hline & Knowing that the activity is doable - that our skills are adequate to the task. \\
\hline & Intrinsic motivation - whatever produces flow becomes its own reward. \\
\hline \multirow[b]{2}{*}{ Feeling } & Completely involved in what we are doing - focused, concentrated. \\
\hline & $\begin{array}{l}\text { A sense of serenity - no worry about oneself and a feeling of growing beyond the } \\
\text { boundaries of ego. }\end{array}$ \\
\hline \multirow[b]{2}{*}{ Result } & A sense of ecstasy - of being outside of everyday reality. \\
\hline & $\begin{array}{c}\text { Timelessness - thoroughly focused on the present, hours seem to pass by in } \\
\text { minutes. }\end{array}$ \\
\hline
\end{tabular}




\subsubsection{HUMAN-COMPUTER INTERACTION}

With the progress of computer and digital processing technologies, the studies of interaction between the human being and the computer via human-computer interfacing devices are getting more and more diversified. Kantowitz and Sorkin [7] proposed a concept of human-computer interfacing from the viewpoint of human factor, which says that a human being has sensors and responders while the computer consists of displays and controls; when the human being uses the sensors to sense a display on the computer screen, the human's brain will react via the responders to activate the controls of the computer to accomplish a desired task by changing its machine state, as illustrated in Figure 1. The concept has been included in the ideas collected in this study for designing the proposed system mentioned previously.

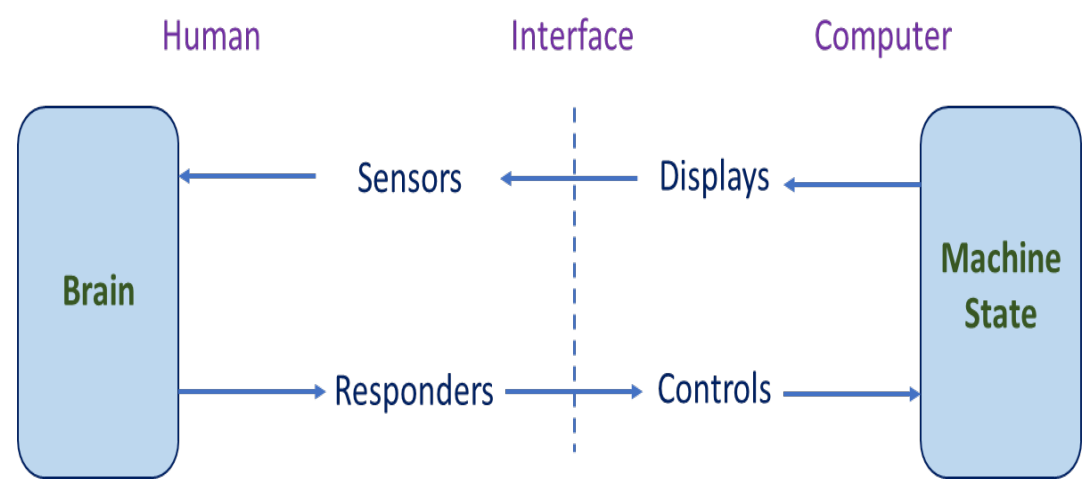

Figure 1: A human-factor view of a human operator in a human-computer interfacing working environment [7].

\subsubsection{DESIGNS OF INTERACTIVE DEVICES AND RELATED CASE STUDIES}

The interactive technology can be used to produce feedbacks from different behavior modes in various applications. Therefore, a user performing an interactive device can obtain more experiences than one using a traditional one. The modern interactive technology not only helps rapid growing of digital engineering systems, but also accelerates applications of many humanity fields, including anthropology, psychology, pedagogy, etc. Interactive installations are the channels for designers to convey their messages or ideas directly. They are also the bridges for people to communicate with computers, creating various interaction models to achieve the designers' goals. Fallman proposed the interaction design research triangle of design practice, design studies, and design exploration [8]. For the part of design exploration, designing is regarded as a new attempt to explore new possibilities. In this study, this concept is introduced into designing and developing an interactive installation equipped with water sensors. The purpose is to create a new water sensing device for a user to get an innovative experience of concentration. The following is a review of some case studies of combining interactive installations with the concept or activity of concentration.

1) "Mindball" [9] - a two-player game based on the EEG methodology, played by wearing brainwave sensors on the head to control the ball direction with the level of relaxation in mind, with the winner being the one successfully moving the ball to the opposite.

2) "Flow of Qi" [10] - a game based on "Qi" produced from the human inner body, with two participants working together on controlling their breaths to "write" calligraphy similarly to the "Pranayama" in Zen.

3) "So-Cal NewsTubular Zen" [11] - a public art installation consisting of a series of tubes which can be touched by people to produce different sounds and lights with the sound resonance making the participant feel the ambiance of Zen around the installation.

4) "Meditation" [12] - a work in a special space generating psychedelic visual effects and sounds to make the participants keep focusing three circles displayed on the screen that can create a ripple effect by mutual interference conducted by the two participants. 
Using A New Water Sensing Device to Design A Novel Interactive Installation for Practicing Concentration to Obtain Flow Experiences

5) "Rain Dance" [13] - a work played by participants who pass through a series of running-down water columns, and by controlling the height of the umbrella, make the original inaudible sound become hearable through the horn shape formed by the top of the umbrella.

6) "Mocean" [14] - an interactive device with a tank of water by which a user can generate sounds by brushing or skimming the water by hand, sprinkle the water, or dipping his/her arms in the water deeply.

7) "Kimapetra" [15] - an interactive artwork with stones surrounding a bowl filled with water, played by putting hands on them to create sonorous vibrations on the water surface that vary according to the intensity of the electrostatic energy of the visitor's body.

8) "HeartWave" [16] - an interactive water-based tabletop device that two players can perform simultaneously to experience the collision, fading out, or even superimposing of two ripples generated by their heart beats, respectively, created by Polar heart beat sensors.

9) "Digidrench" [17] — an interactive video installation by which the user controls the video playback by filling and draining three tanks with the display screen showing liquid falling on the head of a corresponding person.

The features of the above-surveyed case studies related to the concepts of Zen or flow, and the involved digital media techniques are summarized in Table 2.

Table 2: Summary of surveyed cases studies of interactive devices related to mind control.

\begin{tabular}{|c|c|c|c|}
\hline Works & Media & Interactive Approach & Feedback \\
\hline Mindball [9] & Brainwave device & $\begin{array}{l}\text { Mind relaxation and } \\
\text { concentration }\end{array}$ & $\begin{array}{l}\text { Rolling direction of the controlled } \\
\text { ball }\end{array}$ \\
\hline Flow of Qi [10] & $\begin{array}{l}\text { Cardiopulmonary signal } \\
\text { sensor }\end{array}$ & $\begin{array}{l}\text { Controlling breaths to } \\
\text { "write" calligraphy }\end{array}$ & $\begin{array}{c}\text { Showing written calligraphy on } \\
\text { the floor }\end{array}$ \\
\hline $\begin{array}{c}\text { So-Cal } \\
\text { NewsTubular Zen } \\
{[11]} \\
\end{array}$ & Outdoor tubes & $\begin{array}{l}\text { Pressing switch buttons by } \\
\text { hand }\end{array}$ & $\begin{array}{l}\text { Yielding resonant sounds and } \\
\text { lights to create a Zen atmosphere }\end{array}$ \\
\hline Meditation [12] & $\begin{array}{l}\text { Infrared camera and hand } \\
\text { motion detection program }\end{array}$ & Waving the hand & $\begin{array}{c}\text { Displaying three circles on the } \\
\text { screen to create a ripple effect by } \\
\text { mutual interference }\end{array}$ \\
\hline Rain Dance [13] & $\begin{array}{c}\text { Falling water columns and } \\
\text { umbrellas }\end{array}$ & $\begin{array}{l}\text { Lifting the umbrella to } \\
\text { interact }\end{array}$ & $\begin{array}{c}\text { Generating audio frequency to } \\
\text { bring participants audio } \\
\text { enjoyment }\end{array}$ \\
\hline Mocean [14] & $\begin{array}{l}\text { Water tank and the users' } \\
\text { hands }\end{array}$ & $\begin{array}{l}\text { Stirring the water to create } \\
\text { ripples }\end{array}$ & $\begin{array}{c}\text { Playing different types of organ } \\
\text { music to produce surrounding } \\
\text { sound }\end{array}$ \\
\hline Kimapetra [15] & $\begin{array}{l}\text { Plants, rocks, and water } \\
\text { bowl }\end{array}$ & $\begin{array}{l}\text { Touching any part of the } \\
\text { rocks }\end{array}$ & $\begin{array}{l}\text { Creating resonance to vibrate the } \\
\text { water }\end{array}$ \\
\hline HeartWave [16] & $\begin{array}{c}\text { Water sink and heartbeat } \\
\text { detection device }\end{array}$ & $\begin{array}{c}\text { Putting hands on the sides } \\
\text { of the sink to measure } \\
\text { heartbeats }\end{array}$ & $\begin{array}{l}\text { Vibrating water and the color- } \\
\text { changing light }\end{array}$ \\
\hline Digidrench [17] & Sink device and water & $\begin{array}{l}\text { Pouring water into the sink } \\
\text { with controlled speed to } \\
\text { play videos }\end{array}$ & $\begin{array}{l}\text { Displayed the video of liquid } \\
\text { falling on the head of a } \\
\text { corresponding person }\end{array}$ \\
\hline
\end{tabular}

\subsection{SUMMARY OF LITERATURE REVIEW AND IDEAS FOR DESIGNING THE PROPOSED SYSTEM}

It can be seen from the cases listed in Table 2 that people would be in the state of Zen or flow when they are involved in activities requiring concentration. In the interaction processes of many of the above cases, water is the medium to control the device, and the design, by creating a suitable environment for the ambiance, enables the user to focus his/her mind on the interaction with the device. Therefore, in this study the concept of concentration through 
interaction will be followed in designing a prototype system for the user to reach the state of Zen or flow, as described in more detail in the following.

1) Reaching the situation of "concentration" - From the above survey, it can be seen that the situation of Zen or flow can be reached through environment creation and human-machine interaction, and the most crucial in the interactive process is for the participant to focus on something to adjust their mindset, i.e., to concentrate on something in mind, and, via this concentration, to adjust the mindset to be in a stable state. Therefore, in this study, it is desired to design an artwork associated with a Zen atmosphere that allows the participant to have self-concentration in the interaction process.

2) Design of the interaction process - According to the above survey, an interaction scheme which makes the user to conduct self-concentration is effective for the user to be immersed in the interactive process. For this aim, it is desirable in this study to use "water" as the medium in the interaction scheme, and to create symbolic feedbacks of concentration like bell sounds to enhance the atmosphere of Zen. Specifically, in this study, the system named "Zen-Drop" is designed to have a shape of a "Bodhi tree" to create a Zen ambiance, and the major interactive step is designed to be the action of "watering the tree."

3) Assessment of the entire study - In this study, it is desired to evaluate the proposed interactive system by a questionnaire survey of the users' opinions about flow experiences. The surveys will be done after the participants complete the interaction process of the proposed system. Specifically, it is desirable to find out the effectiveness of the system in the aspect of helping the participant conducting concentration through the interaction scheme, and to improve the system according to the investigation result for future developments and researches.

\section{METHODOLOGY}

\subsection{OVERVIEW}

The research methods adopted in this study include: literature review, prototyping, questionnaire survey, expert interview, and system evaluation. Firstly, a literature review was conducted to establish the principles for designing the proposed system. The results have been reported previously in Section 1. Secondly, a prototype was constructed according to the design principles, which will be described later in Section 3. Thirdly, the prototype system was shown in a public exhibition to carry out a field experiment, and visitors were invited to use the prototype system. After interacting with the system, each participant was invited further to fill in a questionnaire pre-designed in this study to express their opinions about the effectiveness of the proposed system. Also invited to the exhibition are several experts who, after observing the users to perform the system, were interviewed by the researcher of this study to express their opinions about the design and the effectiveness of the proposed system. Their opinions were collected. The entire process of the actions taken in the field experiment is shown in Figure 2. Finally, analyses and evaluations of the collected opinion data were conducted to check the effectiveness of the proposed "Zen-Drop" system.

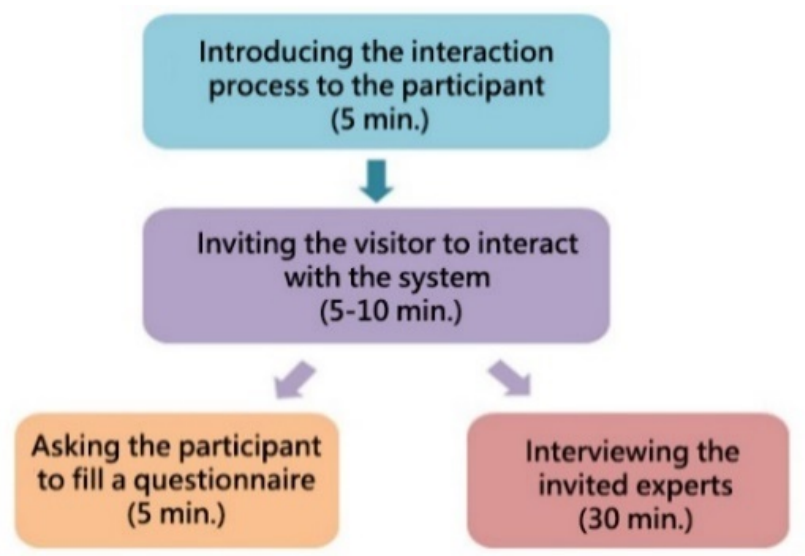

Figure 2: The process of actions taken in the field experiment during the public exhibition of the proposed system. 
Using A New Water Sensing Device to Design A Novel Interactive Installation for Practicing Concentration to Obtain Flow Experiences

\subsection{PROTOTYPING}

Eliason [18] proposed the viewpoint that a system development process should include four steps: demand analysis, system design, prototype establishment, and prototype evaluation. These major steps of interactive system development were followed in the design of the proposed system, as described in the following:

1) Demand Analysis - analyzing the features of Zen and flow situations as well as the requirements of the interactive process based on literature reviews and investigations of people's ideas of living in the modern society;

2) System Design - designing accordingly a prototype system with a suitable interactive process to offer the participant a tool for conducting concentration;

3) Prototype Establishment - constructing the hardware and software of the interactive prototype and testing it until it works fine; and

4) Prototype Evaluation - exhibiting the prototype system in the field experiment and collecting the opinions by questionnaire surveys and expert interviews to examine the effectiveness of the work in bringing the ambiance of concentration.

\subsection{QUESTIONNAIRE DESIGN}

The questions included in the questionnaire were designed to reflect the seven situations of the flow experiences which belong to three aspects, namely, condition, feeling, and result, as described in Table 1, in order to explore the relation between the involvement in the flow situation and the interactive process provided by the proposed "ZenDrop" system. In detail, totally 11, 8, and 6 questions were designed for the three aspects, respectively. The structure of the situations and the aspects are illustrated in Figure 3.

In addition, the 5-point Likert Scale [19] was adopted to specify the degrees of agreement of the answers to each question, including "strongly disagree," “disagree," "neither agree nor disagree," "agree," and "strongly agree," which are given the scores of 1 through 5. Later, in a pre-test of the initially-designed questionnaire, it was found that the meaning of the middle choice, "neither agree nor disagree," is vague to many respondents; therefore, it was eliminated later, resulting in the use of a 4-point scale with the scores of 1 to 4 being given to the choices of "strongly disagree," "disagree," "agree," and "strongly agree," respectively.

It is mentioned by the way that a pre-test of the questionnaire has been conducted, in which two experts were invited to give comments about the wording in the questions of the questionnaire and to confirm the appropriateness of the question contents for assessing the characteristics of flow experiences, resulting in the final version of the questionnaire with thirty questions, whose details will be presented later in this paper.

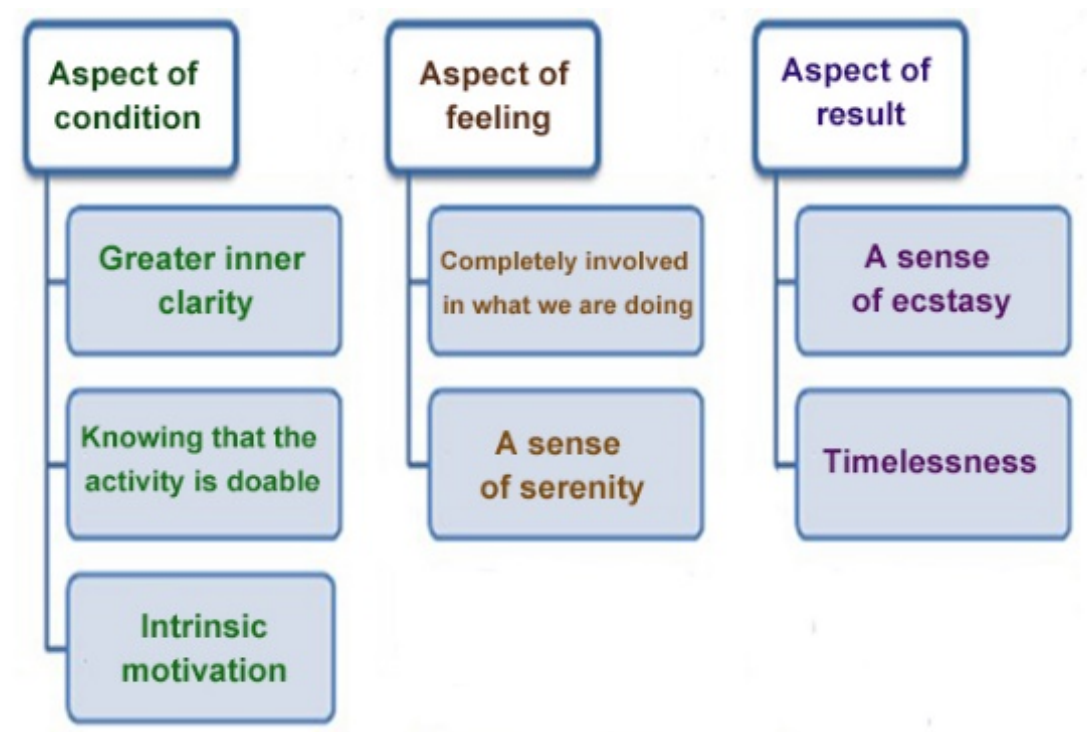

Figure 3: The structure of the three aspects of the questionnaire questions based on flow experiences. 


\subsection{INTERVIEWS WITH EXPERTS}

As mentioned previously, expert interviews have been conducted in this study during the period of the public exhibition of the proposed "Zen-Drop" system. Totally, three experts were invited whose expertises are listed in Table 3. They all have experiences of using interactive systems similar to the one proposed in this study. They were invited, not only to use the proposed system to have feelings of the system's performance, but also to observe the interactive processes of other users, before the interviews were started. The topics of the interview include: 1) the feedback of the interactive process of the system; 2) the degree of concentration of the participant; and 3) the usability of the interfaces for performing the interaction process. The opinion data collected from the interviews were used for evaluating the effectiveness of the proposed system, which will be presented later in this paper.

Table 3: A list of the backgrounds and expertises of the experts invited for interviews in this study.

\begin{tabular}{|c|c|c|c|}
\hline No. & Organization & Occupation & Expertise \\
\hline A & religious college & president & experience of meditation, use of electroencephalograph \\
\hline B & religious college & project manager & philosophy, research of concentration \\
\hline C & national university & associate professor & user interface design, innovative thinking \\
\hline
\end{tabular}

\subsection{SYSTEM EVALUATION}

The opinion data collected in the expert interviews and questionnaire surveys were used for evaluating the effectiveness of the proposed "Zen-Drop" system. Specifically, the data for the four aspects of the questions of the questionnaire as shown in Figure 3 will be evaluated respectively to prove the various issues of effectiveness of the proposed system as shown in Table 4 and described in the following.

1) Aspect of condition- This aspect includes three situations, "great inner clarity," "knowing that the activity is doable," and "intrinsic motivation." For these situations in this aspect, the evaluation is aimed at exploring the user experiences about the completeness of the interaction process, the visual and auditory feedbacks of the system, and the participant's capability to complete the interaction process.

2) Aspect of feeling - This aspect includes two situations, "completely involved in what we are doing" and "a sense of serenity." For these situations, it is desired in the evaluation to explore the issues of whether the participants have reached self-control and self-concentration during the interaction process.

3) Aspect of result -This aspect includes two situations, "a sense of ecstasy" and "timelessness." For this aspect, it is desirable to evaluate the participants' feeling of timelessness when they concentrated in performing the system, as well as their experiences and enjoyment after completing the interaction process.

Table 4: Evaluation issues contained in the questionnaire corresponding to the situations of the flow experiences shown in Figure 3.

\begin{tabular}{|c|c|c|}
\hline Aspect & $\begin{array}{c}\text { Situation of } \\
\text { flow/interaction }\end{array}$ & Issue investigated in the evaluation \\
\hline \multirow[t]{3}{*}{ Condition } & Great inner clarity & $\begin{array}{l}\text { the user experiences about the completeness of the interaction process } \\
\text { and the concept of Zen conveyed by the system - "focus on meditation" }\end{array}$ \\
\hline & $\begin{array}{l}\text { Knowing that the activity is } \\
\text { doable }\end{array}$ & whether the participant can complete the interaction process \\
\hline & Intrinsic motivation & $\begin{array}{l}\text { the user experience about the visual and auditory feedbacks of the } \\
\text { system }\end{array}$ \\
\hline \multirow[t]{2}{*}{ Feeling } & $\begin{array}{l}\text { Completely involved in } \\
\text { what we are doing }\end{array}$ & $\begin{array}{l}\text { whether the participant have reached self-concentration during the } \\
\text { interactive process }\end{array}$ \\
\hline & A sense of serenity & $\begin{array}{l}\text { whether the participant have reached self-control during the } \\
\text { interactive process }\end{array}$ \\
\hline \multirow[t]{2}{*}{ Result } & A sense of ecstasy & the user's experience and enjoyment after the interaction \\
\hline & Timelessness & $\begin{array}{c}\text { the user's feeling of the flying time when they concentrated in } \\
\text { performing the system }\end{array}$ \\
\hline
\end{tabular}




\section{FINDINGS AND DISCUSSIONS}

\subsection{DESIGN CONCEPT OF THE PROPOSED SYSTEM}

People's self-regulation of "growing inherent kindness" and "concentrating with tranquility" is emphasized in the concept of Zen. And in the "Twenty-five Yuantong Meditation" methods for Zen cultivation, there exist the idea of applying the so-called "great water" technique. It is tried in this study to follow such an idea to design a water-based interactive system, the "Zen-Drop," which, via the performance of pouring water stably into a collector, allows a participant to experience the interchange between water and the mindset while listening to the sound of natural water flow in the water pouring process, and so to feel the ambience of concentration. Note that here the aim is not the Zen meditation, but the mind concentration.

The interactive installation for this way of water-based concentration is illustrated in Figure 4, which, as can be seen, is of the shape of a Bodhi tree, and it can be performed by pouring water into the top of the tree trunk to generate feedbacks of sounds issued via a speaker put aside the tree and color changes occurring on the tree leaves, which represent different degrees of concentration reached by the participant. Inside the tree is a water sensing device newly designed in this study for determining if the water pouring action conducted by the participant is successful or not, or equivalently, for deciding if the participant's trial of self-control of the hand operation to accomplish selfconcentration in mind is effectively completed. More details will be presented later in this paper.

\subsection{ARCHITECTURE OF THE PROPOSED SYSTEM}

The proposed "Zen-Drop" system designed in this study is a tangible interactive device with four wheels, facilitating moving to anywhere for conducting experiments and public exhibitions. Its architecture is introduced in this section, which is described briefly at first in the following:

1) Physical System Setup - including a Bodhi tree with a trunk, four leaves, four wheels and a water bucket and a scoop for water pouring;

2) Hardware - including a computer as the main processing unit, a water-sensing device built in the tree, a circuit for LED light triggering, sound playing, and water-drainage control; and

3) Software - including programs for performing the functions of water sensing, water-pouring stability decision, LED visual feedbacks, sound feedbacks, and water drainage.

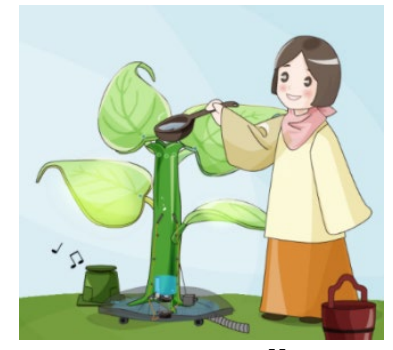

Figure 4: The structure of the interactive part, a Bodhi tree, of the proposed "Zen-Drop" system.

\subsubsection{CONCENTRATION ASSESSMENT BY WATER SENSING}

The system uses water as the sensing medium, aiming at offering a tool for assessing the goodness of the participant's practice of concentration by controlling his/her water-pouring action. The hardware, a water-sensing device, and the software, the related water pouring detection scheme, proposed in this study for this aim are described here. A simple illustration of the idea of water sensing using a simple circuit is shown in Figures 5(a) and 5(b), where water is used as an electric conductive medium to light up a small LED bulb. Specifically, Figure 5(a) shows an open electric circuit consisting a pair of unconnected wire ends, and Figure 5(b) shows a close circuit using the water in a cup as the electric conductor, with the generated electric current lighting up an LED bulb. When the LED bulb is hidden 
in a leaf of the Bodhi tree, it seems that the leaf is brightened by the water medium through the vein of the tree, as shown in Figure 5(c). In this way, a pair of open-circuit wire ends may be used as a water sensor, as done in this study. By using such a type of water sensor, two functions for concentration assessment are created in this study for use in the proposed "Zen-Drop" system, as described in the following and illustrated in Figures 5(d) and 5(e).

\section{Tree-Leaf Lighting Control by Water-Level Detection}

The above-mentioned water sensor is used three times as water-level detectors in the tree trunk as shown in Figure 5(d), in which each pair of small circles drawn on the tree trunk represents one of such water-level detectors: as long as the amount of water poured into the tree trunk from the tree top by the user grows gradually to reach the height of a water-level detector of the three, the electricity generated by the resulting close circuit through the water will light up a pair of the tree leaves in green as an indication of successful on-going water pouring.

\section{Water-Pouring Stability Detection}

The above-mention water sensor is also used as a pouring-stability detector which is located on top of the three water-level detectors as shown in Figure 5(d), with its top view illustrated in Figure 5(e) in which the concentric blue part is a ring of thick stainless iron sheet slanted outward with a pair of holes located on each side of the ring that are connected to a pair of open wire ends, forming a water detector. That is, the pouring-stability detector consists of an iron ring with two water detectors located at its two sides, respectively. If water is poured unstably by a user to fall on the slanted iron ring, the water will flow to at least one side of the ring to fill the two holes of the water detector there, creating a close electric circuit to light up a pair of tree leaves in red as a warning to the user.

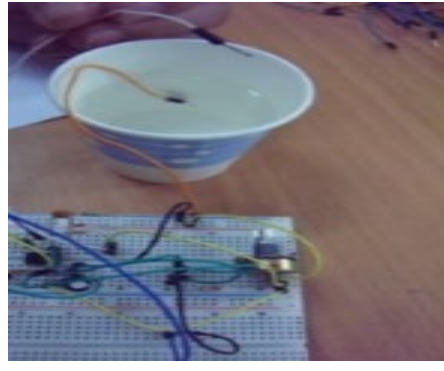

(a)

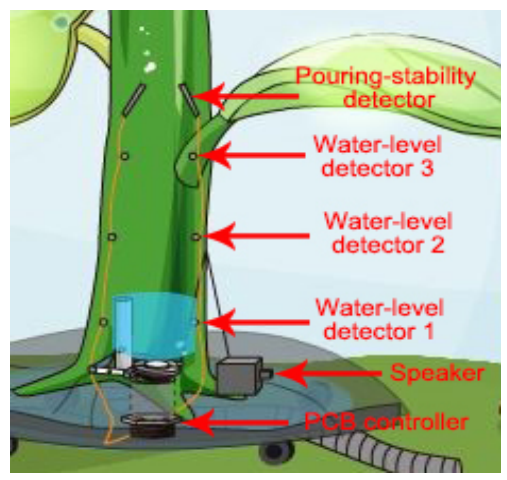

(d)

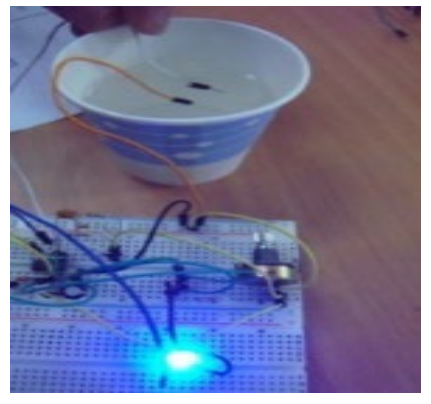

(b)

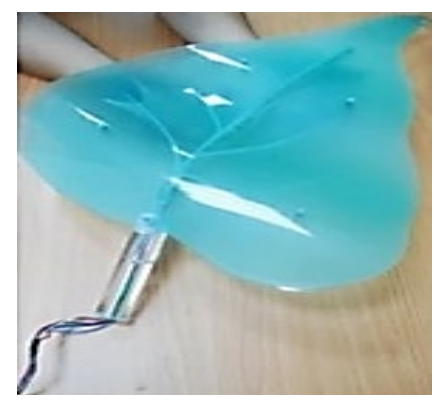

(c)

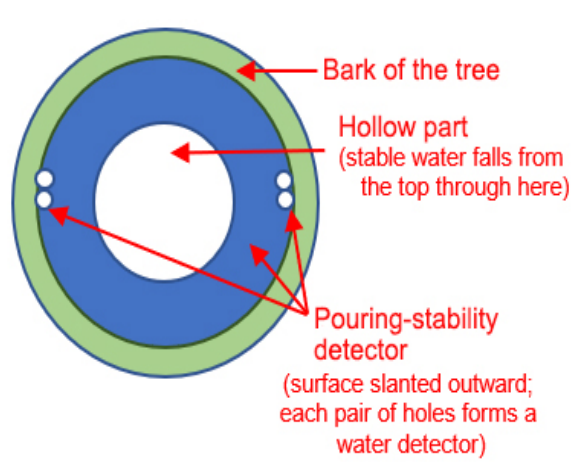

(e)

Figure 5: The techniques used in "Zen-Drop" for concentration assessment. (a) The hardware, the electrical circuit of the water sensor, in an open state. (b) The circuit of the water sensor in a close state, with the generated electricity lighting up an LED bulb (c) A color-changeable leave of the Bodhi tree with the color LED hidden inside. (d) The Bodhi tree with a water sensing device including four water sensors, three water-level detectors, and one pouring-stability detector, built in the tree trunk. (e) The top view of the pouring-stability detector. 


\subsubsection{PHYSICAL SHAPE DESIGN}

About the design of the exterior shape of the Bodhi tree, a line draft was generated at first at the beginning stage of this study, and a prototype was built accordingly as shown in Figure 6(a). The mobility of the work was enhanced by creating a movable wooden base with four wheels. The exterior texture of the base was made to be a rock, and the trunk of the tree is made of glass fiber, as shown in Figure 6(b). The four leaves are made of acrylic material which are attached to the tree trunk, as shown in Figure 6(c). The color of the leaves, which is created by lighting using LED bulbs hidden inside, will change in accordance with the level of the water poured into the tree trunk, as shown in Figure 6(d). Finally, a water bucket and a scoop, both made of wood, were constructed for water pouring conducted by the user, as shown in Figure 6(e).
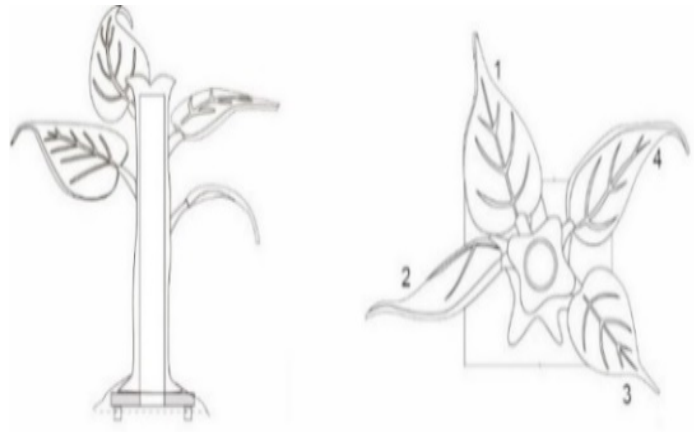

(a)

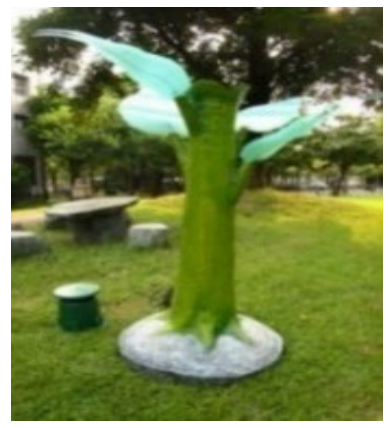

(c)

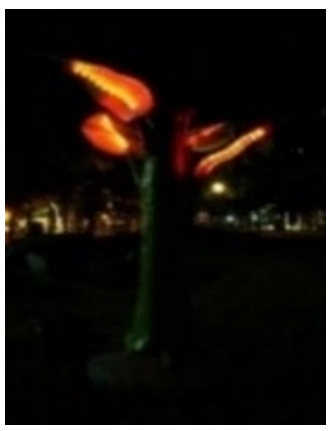

(d)

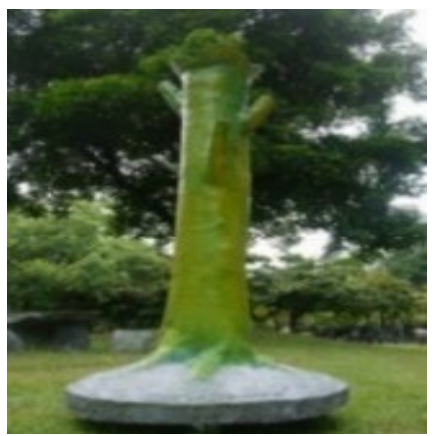

(b)

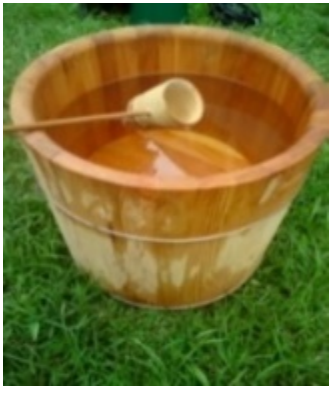

(e)

Figure 6: Construction of the Bodhi tree in the proposed "Zen-Drop" system. (a) A line draft of the design of the tree. (b) The trunk of the tree made of glass fiber. (c) The complete tree with attached leaves made of acrylic material. (d) The Bodhi tree seen at night with the leaves lit in a red color. (e) The wood bucket and the scoop for water pouring.

\subsubsection{DESIGNS OF THE HARDWARE AND SOFTWARE FUNCTIONS}

A printed circuit board (PCB) with an Arduino chip and some associated circuits as shown in Figure 7 is equipped at the root part of the Bodhi tree as the main controller in the proposed "Zen-Drop" system (denoted as the PCB controller at the bottom of Figure $5(\mathrm{~d})$ ), which, by utilizing water as the sensing medium, carries out three major processes in the system, namely, water pouring stability detection, water-level sensing, and water drainage control, as described in the following.

\section{Water Pouring Stability Detection for Concentration Assessment}

Being equipped inside the trunk of the Bodhi tree, the water-level and pouring-stability detectors begin their respective detection functions when the participant begins to pour water into the trunk of the Bodhi tree from the top. The leaves of the tree will be brightened in green or red as the water flows through the detectors as described 
previously. Specifically, the Bodhi tree leaves will start to brighten in red as a warning when the user pours water unstably (i.e., when water is not poured right through the hollow part of the tree trunk but onto the iron ring of the pouring-stability detector to form a close circuit). And each time an unstable water pouring is detected, after a pair of tree leaves are lit up in red, the interactive process is started over again from the beginning of the water pouring process. After having detected water-pouring instability three times, all leaves will become red as an indication that the participant pays insufficient attention in the tree watering process. On the contrary, all leaves will become green if water pouring is conducted successfully to pass the three times of water-level detection as described next.

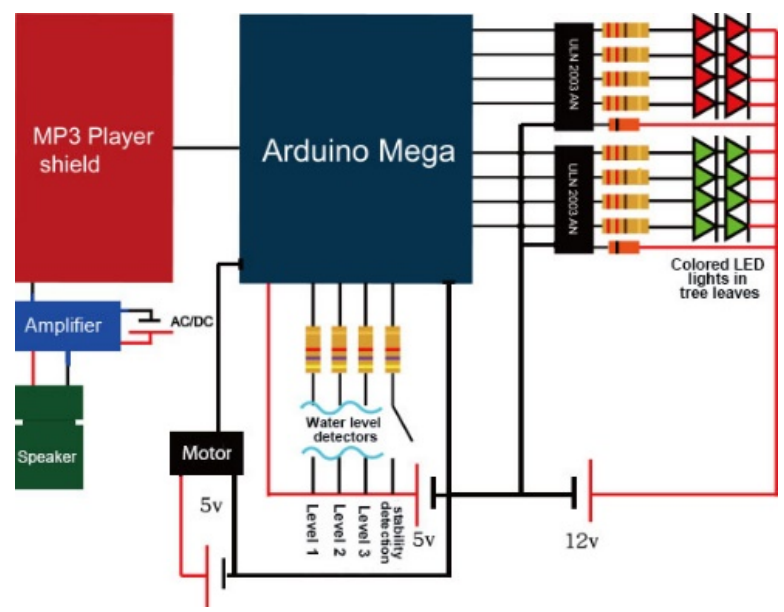

Figure 7: The circuit diagram of the PCB controller used as the core hardware hidden in the trunk of the Bodhi tree for sensing and controlling the functions of the "Zen-Drop" system.

\section{Water-Level Sensing for Lasting-Attention Detection}

If the water pouring process conducted by the participant lasts stably for a sufficiently long time, all the three water-level detectors inside the tree trunk will be passed by the height-rising water to light up the tree leaves. Specifically, when the water reached the first water-level detector, a signal will be sent to the Arduino chip that then lights up two tree leaves in green (via the ULN2003AN chips which control the switching and the RGB colors of the LED bulbs as shown in the right portion of Figure 7) and issues a long bell sound in the meantime (via the sound hardware part including an MP3 player shield chip, an amplifier, and a speaker as shown in the left portion of Figure 7). As the water accumulates to reach the second water-level detector, the same is performed to light up two more leaves in green and issue two long bell sounds. Finally, when the third water-level detector is reached by the rising water, all the four lit-up leaves in green will flicker for several seconds, and a human voice saying the word "Amitabha" is played, indicating that the user's concentration on water pouring has lasted long enough.

Water drainage control at the end of a successful water pouring process -

Being connected to a drain cover, the motor seen in the lower portion of Figure 7 will begin to work to carry out water drainage as the poured water accumulates to the third water-level detector. Specifically, the motor will have a 90-degree rotation to pull the drain cover to let out the water inside of the trunk of the Bodhi tree, getting the system ready for the next run.

\subsection{AN ALGORITHM OF THE INTERACTIVE PROCESS OF “ZEN-DROP”}

An algorithm describing the details of the above-mentioned interactive process of the "Zen-Drop" system is given in this section, followed by an illustrative example of the intermediate results yielded by running the algorithm. Some notations and terms used in the algorithm are defined in advance in the following:

1) signal, $S_{i}$ with $i=1,2,3$, which is issued by the PCB controller when the poured water reaches water-level detector $i$ illustrated in Figure 5(d), i.e., for $i=1,2,3, S_{i}$ is set to be 1 if water-level detector $i$ detects the existence of water (set automatically by the water-level detector $i$ ); otherwise, to be 0 ;

2) signal, $G_{i}$ with $i=1,2,3,4$, which is issued by the PCB controller to light up the green LED bulb inside the $i$-th leaf of the Bodhi tree, i.e., for $i=1,2,3,4$, set $G_{i}$ to be 1 if the green bulbs inside the $i$-th leaf of the Bodhi tree is to be lit up; otherwise, to be 0 ; 
3) signal, $R_{i}$ with $i=1,2,3$, 4, which is issued by the PCB controller to light up the red LED bulb inside the $i$-th leaf of the Bodhi tree, i.e., for $i=1,2,3,4$, set $R_{i}$ to be 1 if the red bulbs inside the $i$-th leaf of the Bodhi tree is to be lit up; otherwise, to be 0 .

4) signal, $U$, which is issued by the PCB controller when unstably-poured water falls onto the concentric ring of the pouring-stability detector and flows into the holes of either water detector at a side of the ring as illustrated in Figure 5(e), i.e., set $U$ to be 1 if the pouring-stability detector detects the existence of water (set automatically by the pouring-stability detector); otherwise, to be 0 ;

5) signal, $M$, which is issued by the PCB controller to trigger the motor when water drainage is to be conducted;

6) counter, $T$, which is the number of times the user pours water unstably into the tree trunk to activate the pouring-stability detector;

7) the $i$-th water level, which is the height of the $i$-th water-level detector.

Algorithm 1. The interactive process of the proposed "Zen-Drop" system.

Input: water poured into the trunk of the Bodhi tree.

Output: the color changes of the leaves of the Bodhi tree and the issued sounds (as illustrated in Table 5 subsequently).

\section{Steps.}

//Initialization - Bodhi tree leaves are lit up in turn to wait for the beginning of water pouring

Step 1: set $T=0, M=0 . \quad$ //Setting initially the times of unstable water pouring and the motor triggering signal to be zero Step 2:

//Lighting up the four tree leaves in turn in green until water pouring is started

2.1 while $U \neq 1$ do

(a) while signal $S_{1} \neq 1$ do

for $i=1$ to 4 do

(i) set $G_{i}=1$ for one second;

(ii) set $G_{i}=0$;

end for;

\section{end while;}

//Stage 1 - Water detected to reach the $1^{\text {st }}$ water level

(b) issue the bell sound once;

(c) while signal $S_{2} \neq 1$ do

(i) set $G_{3}=0$, and $G_{4}=0$;

(ii) set $G_{1}=1$ for one second;

(iii) set $G_{2}=1$;

end while;

//Stage 2 - Water detected to reach the $2^{\text {nd }}$ water level

(d) issue the bell sound twice;

(e) while signal $S_{3} \neq 1$ do

(i) set $G_{1}=1$, and $G_{2}=1$;

(ii) set $G_{3}=1$ for one second;

(iii) set $G_{4}=1$;

end while;

//Stage 3 -Water detected to reach the $3^{\text {rd }}$ water level

(f) issue the human voice saying the word "Amitabha";

(g) for $j=1$ to 5 do

(i) set $G_{1}$ through $G_{4}=1$ for $1 / 2$ second;

(ii) set $G_{1}$ through $G_{4}=0$ for $1 / 2$ second;
//Indicating the poured water has reached water level 1

$/ /$ Lighting up the $1^{\text {st }}$ and the $2^{\text {nd }}$ tree leaves in green in order

//Indicating the poured water has reached level 2

//Keeping lighting the $1^{\text {st }}$ and the $2^{\text {nd }}$ tree leaves in green $/ /$ Lighting up the $3^{\text {rd }}$ and the $4^{\text {th }}$ tree leaves in green in order

//Indicating the poured water has reached level 3 //Flickering all the four tree leaves in green five times $/ /$ Lighting up all the tree leaves in green for $1 / 2$ second //Stopping lighting all the leaves 
end for;

(h) goto Step 1; end while.
//Going to the start another run of the process //End of looping with no water-pouring instability detected

//Any stage - Water detected to be poured unstably now

\section{Step 3:}

\section{1 if $T \neq 3$ then}

(a) set $R_{T+1}=1$;

(b) $\operatorname{set} T=T+1$;

(c) set $U=0$;

(d) issue a deep sound;

(e) goto Step 2;

else

(f) for $i=1$ to 4 do

(i) set $R_{i}=1$ for two second;

(ii) set $R_{i}=0$;

end for;

(g) issue a deep sound;

(h) set $M=1$;

(i) goto Step 1; end if.
//Water detected to be poured unstably less than three times //Lighting up the $(T+1)$-th tree leaf in red as a warning

//Incrementing the times of detected unstable water pouring //Resetting the pouring-instability signal //Indicating a warning of instability //Going to start water pouring over again //Water detected to be poured unstably for three times //Lighting up all the four tree leaves in red as a serious warning //Lighting up the $i$-th tree leaf in red //Stopping lighting the $i$-th leaf in order to light up the next

//Indicating a warning of instability

//Triggering the motor to carry out water drainage //Going to the start for another run of the system //End of the algorithm

Note that the water pouring operations to pass the three water levels in Step 2 of the above algorithm can be accomplished only when the condition in the while-loop, "signal $U \neq 1$," is satisfied, i.e., only when the pouringinstability detector does not detect any unstable watering action; otherwise, the program will jump to Step 3 where the operations will enforce the user either to go to Step 2 to start water pouring over again, or to go to Step 1 to restart the entire process. That is, the user must water the tree stably to pass the three water levels continuously with no failure; otherwise, he/she has to repeat the process again. It is in this way that the proposed "Zen-Drop" system can train solidly the user to practice concentration in mind!

Several steps in the above algorithm are designed to express certain meanings of Zen, as described in the following.

1) Step 2.1(a): lighting up in turn the four leaves of the Bodhi tree when it is quiet at the beginning with nobody present around - expressing the meaning that the energy of heaven and earth circulates to each other with the movement of stillness.

2) Stage 1 - Steps 2.1(b) \& (c): lighting up tree leaves 1 and 2 (the lower two) in green in order - expressing the meaning that the user, via pouring water of compassion, creates kindness in his/her heart.

3) Stage 2 - Steps 2.1(d) \& (e): lighting up tree leaves 3 and 4 in green in order - expressing the meaning that while the user continues to pour water, via the audio-visual effect, more compassion is collected, which echoes the kindness created in the user's heart.

4) Stage 3 - Steps 2.1(f)-(h): lighting up all four tree leaves in green, flickering for several seconds, and issuing the sound of 'Amitabha' - expressing the meaning that the flickering tree leaves and the sound of 'Amitabha' are congratulations to the user's full collection of water of compassion.

5) Any stage - Steps 3.1(a)-(e): lighting up one more tree leaf in red and issuing a deep sound - expressing the meaning that the red tree leave and the deep sound are warnings of unstable water pouring.

6) Any stage - Steps 3.1(e)-(i): lighting up all the four tree leaves in red and issuing a deep sound - expressing the meaning that the four red tree leaves and the deep sound are serious warnings of unstable water pouring. 5.

An example of intermediate results yielded by running the "Zen-Drop" interactive system is illustrated in Table 
Table 5: An Example of Results of Running the "Zen-Drop" Interactive algorithm.

\begin{tabular}{|c|c|c|c|c|c|c|}
\hline No. & Interaction step & Illustration & Visual effect & Sound & Explanation & $\begin{array}{l}\text { Step } \\
\text { No. }\end{array}$ \\
\hline 1 & Initialization & & $\begin{array}{l}\text { It is quiet around } \\
\text { with nobody } \\
\text { present; the four } \\
\text { tree leaves are lit up } \\
\text { one by one. }\end{array}$ & No & $\begin{array}{l}\text { The energy of heaven } \\
\text { and earth circulates to } \\
\text { each other with the } \\
\text { movement of stillness. }\end{array}$ & $\begin{array}{l}\text { Step } \\
2.1(\mathrm{a})\end{array}$ \\
\hline 2 & $\begin{array}{c}\text { Stage 1: } \\
\text { beginning to } \\
\text { pour water }\end{array}$ & & $\begin{array}{l}\text { Tree leaves } 1 \& 2 \\
\text { are lit up in green in } \\
\text { order (note: the red } \\
\text { arrow points to the } \\
\text { reached water level) }\end{array}$ & $\begin{array}{l}\text { A long bell } \\
\text { sound }\end{array}$ & $\begin{array}{c}\text { The user, via pouring } \\
\text { water of compassion, } \\
\text { creates kindness in } \\
\text { his/her heart. }\end{array}$ & $\begin{array}{l}\text { Steps } \\
2.1(\mathrm{~b}) \\
\&(\mathrm{c})\end{array}$ \\
\hline 3 & $\begin{array}{c}\text { Stage 2: } \\
\text { continue to } \\
\text { pour water }\end{array}$ & & $\begin{array}{l}\text { Tree leaves } 1 \text { and } 2 \\
\text { keep lighting in } \\
\text { green; and leaves } 3 \\
\text { and } 4 \text { are lit up } \\
\text { additionally in green } \\
\text { in order }\end{array}$ & $\begin{array}{l}\text { Two long } \\
\text { bell sounds }\end{array}$ & $\begin{array}{l}\text { While the user continues } \\
\text { to pour water, via audio- } \\
\text { visual effect, more } \\
\text { compassion is collected, } \\
\text { echoing kindness created } \\
\text { in the user's heart. }\end{array}$ & $\begin{array}{l}\text { Steps } \\
2.1(\mathrm{~d}) \\
\&(\mathrm{e})\end{array}$ \\
\hline 4 & $\begin{array}{l}\text { Stage } 3 \text { (last } \\
\text { stage): water } \\
\text { pouring } \\
\text { completed }\end{array}$ & & $\begin{array}{c}\text { All tree leaves } 1 \\
\text { through } 4 \text { are lit up } \\
\text { in green and flicker } \\
\text { for several seconds }\end{array}$ & $\begin{array}{c}\text { A human } \\
\text { voice saying } \\
\text { 'Amitabha' }\end{array}$ & $\begin{array}{l}\text { The flickering tree leaves } \\
\text { and sound of 'Amitabha' } \\
\text { congratulate the user's } \\
\text { full collection of water of } \\
\text { compassion. }\end{array}$ & $\begin{array}{l}\text { Steps } \\
2.1(\mathrm{f})- \\
\text { (h) }\end{array}$ \\
\hline 5 & $\begin{array}{l}\text { Any stage: } \\
\text { water pouring } \\
\text { unstable }\end{array}$ & & $\begin{array}{l}\text { One more tree leaf is } \\
\text { lit up in red }\end{array}$ & $\begin{array}{l}\text { A deep } \\
\text { sound }\end{array}$ & $\begin{array}{c}\text { The red tree leave and } \\
\text { the deep sound are } \\
\text { warnings of unstable } \\
\text { water pouring. }\end{array}$ & $\begin{array}{l}\text { Steps } \\
3.1(\mathrm{a})- \\
\text { (e) }\end{array}$ \\
\hline 6 & $\begin{array}{c}\text { Any stage: } \\
\text { water poured } \\
\text { unstably for } \\
\text { three times }\end{array}$ & & $\begin{array}{l}\text { All four tree leaves } \\
\text { are lit up in red }\end{array}$ & $\begin{array}{l}\text { A deep } \\
\text { sound }\end{array}$ & $\begin{array}{l}\text { The four red tree leaves } \\
\text { and the deep sound are } \\
\text { serious warnings of } \\
\text { unstable water pouring. }\end{array}$ & $\begin{array}{l}\text { Steps } \\
\text { 3.1(f)- } \\
\text { (i) }\end{array}$ \\
\hline
\end{tabular}

\subsection{PUBLIC EXHIBITION AS FIELD EXPERIMENT}

In the public exhibition of the "Zen-Drop" system, the exhibition space was decorated with sands and rocks to create the ambiance of Zen. The leaves of the Bodhi tree are brightened initially to draw the passerby's attention so that he/she can be invited to participate in the interactive water pouring process of the system. When the participant was watering the Bodhi tree with the wooden scoop, various audio-visual feedbacks are provided by the system by sensing his/her performance of mind concentration and hand control. The system will issue the human voice "Amitabha" and light up all the tree leaves in green if the participant finishes the interaction process successfully. The duration of a successful watering activity was approximately five to ten minutes. Some scenes of participants conducting the interactive process of Bodhi-tree watering are shown in Figures 8(a) through 8(c). At the end of the process, the participant's opinions about the performance of the system are collected for further analysis by conducting a questionnaire survey, as shown by Figure 8(d). 


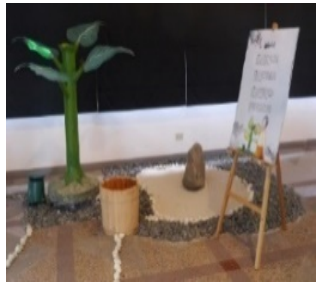

(a)

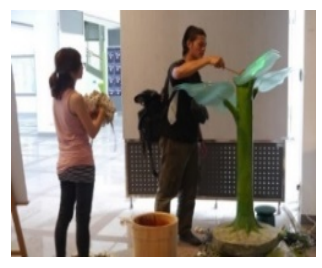

(b)

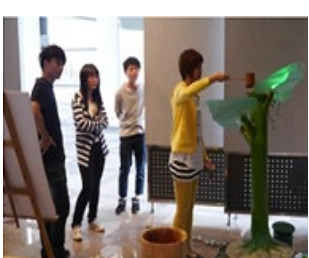

(c)

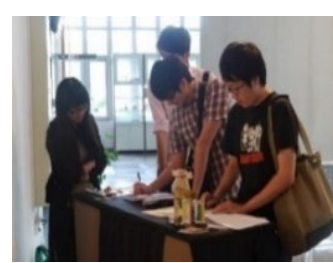

(d)

Figure 8: The environment and participants in the public exhibition of "Zen-Drop". (a) The decoration of the exhibited Bodhi tree. (b) A participant interacting with the tree by water pouring. (c) Another participant interacting with the tree with some observers. (d) Participants filling the questionnaires.

\subsection{ANALYSES OF QUESTIONNAIRE SURVEY DATA}

In this study, the respondents to the questionnaire surveys were the participants who finished the interactive process successfully. 49 valid questionnaires were collected from a total of 52 participants. In the evaluation of the collected opinion data, firstly, the sample structure of the distribution of the respondents was analyzed, yielding the facts that 63.3 percent of the participants were male and 36.7 percent female, and that the majority age group includes 23 respondents with ages ranging from 20 to 25, and accounts for 46.9 percent of the total.

Secondly, analyses of the collected opinion data about the issues shown in Table 4 using the 4-point Likert scale were conducted using the SPSS statistics software package. The questions designed for use in the questionnaire surveys and the statistic results of the scores of the answers, including the means, modes, and standard deviations (S. D.), are listed in Table 6.

\subsubsection{OVERALL EVALUATION OF THE COLLECTED QUESTIONNAIRE DATA}

From the table, it can be seen that all the mean values of the scores of the answers to the questions are larger than 2.5, meaning that the overall degree of agreement with the contents of the questions in the questionnaire is positive, considering the score range being from 1 to 4 . Especially, five questions (highlighted in the table in light gray) are seen to have the highest mode values 4 with highest mean values close to or larger than 3.5 as listed in the following and shown in Table 7:

Question 8: I see brightening leaves during interaction with Zen-Drop.

Question 9: I hear the bell sound while interacting with the system.

Question 11: I notice the auditory feedback of Zen-Drop.

Question 16: The interactive approach is simple to me.

Question 25: In further interaction with Zen-Drop, I will be confident of doing it better.

These questions are all about the audio-visual feedbacks from or the interactions with the proposed "Zen-Drop" system. From the frequency data listed in Tables 8, 10, and 12 shown later, it can be seen that for these questions, more than $90 \%$ of the 49 respondents either agree or strongly agree with the contents of the questions. Therefore, it can be concluded that the proposed system has good feedbacks to and effective interactions with the participants.

\subsubsection{ANALYSIS OF THE RELIABILITY OF THE COLLECTED QUESTIONNAIRE DATA}

The reliability of the collected opinion data must be analyzed before they can be used for evaluations of the effectiveness of the proposed system. For this aim, the Cronbach's alpha coefficient is adopted; if the computed Cronbach's alpha coefficient is larger than 0.7, the collected data are usually decided to be reliable [20], [21], [22]. Accordingly, since the Cronbach's alpha coefficient values for the four aspects of questions in the questionnaires computed in this study are $0.774,0.762,0.785$, and 0.636 , respectively, as shown in Table 8 , it means that the answer data of the four aspects are all reliable for further uses to evaluate the effectiveness of the proposed "Zen-Drop" system. 
Using A New Water Sensing Device to Design A Novel Interactive Installation for Practicing Concentration to Obtain Flow Experiences

Table 6: Questions for the questionnaire survey and statistics of scores of the users' answers.

\begin{tabular}{|c|c|c|c|c|c|c|}
\hline No. & Aspect & $\begin{array}{l}\text { Situation of } \\
\text { "flow" }\end{array}$ & Descriptions & Mean & Mode & S. D.* \\
\hline 1 & \multirow{11}{*}{$\begin{array}{l}\text { Aspect of } \\
\text { condition }\end{array}$} & \multirow{3}{*}{$\begin{array}{l}\text { Great inner } \\
\text { clarity }\end{array}$} & I understand the whole interaction process. & 3.18 & 3 & .601 \\
\hline 2 & & & I know how to interact with the installation. & 3.33 & 3 & .591 \\
\hline 3 & & & I know the purpose of the Zen-Drop system. & 3.12 & 3 & .564 \\
\hline 4 & & \multirow{3}{*}{$\begin{array}{l}\text { Knowing that } \\
\text { the activity is } \\
\text { doable }\end{array}$} & I think I could instantly operate the installation. & 3.10 & 3 & .684 \\
\hline 5 & & & I have not noticed the red leaves during the interaction. & $2.67^{*}$ & $3 *$ & $1.162^{*}$ \\
\hline 6 & & & I believe I could finish the whole process. & 3.08 & 3 & .672 \\
\hline 7 & & \multirow{5}{*}{$\begin{array}{l}\text { Intrinsic } \\
\text { motivation }\end{array}$} & I know that I did well during the interaction. & 3.00 & 3 & .707 \\
\hline 8 & & & $\begin{array}{l}\text { I see brightening leaves during interaction with Zen- } \\
\text { Drop. }\end{array}$ & 3.80 & 4 & .407 \\
\hline 9 & & & I hear the bell sound while interacting with the device. & 3.76 & 4 & .480 \\
\hline 10 & & & $\begin{array}{l}\text { I know whether I have concentrated from the tree leaf } \\
\text { colors. }\end{array}$ & 3.33 & 3 & .591 \\
\hline 11 & & & I notice the auditory feedback of Zen- Drop. & 3.71 & 4 & 456 \\
\hline 12 & \multirow{8}{*}{$\begin{array}{l}\text { Aspect of } \\
\text { feeling }\end{array}$} & \multirow{5}{*}{$\begin{array}{c}\text { Completely } \\
\text { involved in } \\
\text { what we are } \\
\text { doing }\end{array}$} & $\begin{array}{l}\text { Interacting with Zen-Drop is an activity that can train } \\
\text { concentration. }\end{array}$ & 3.20 & 3 & .577 \\
\hline 13 & & & $\begin{array}{l}\text { I can easily control the water volume while watering } \\
\text { the installation. }\end{array}$ & 3.08 & 3 & .672 \\
\hline 14 & & & I can successfully pour water into the installation. & 3.33 & 3 & .591 \\
\hline 15 & & & $\begin{array}{l}\text { Interacting with Zen-Drop is an activity that can train } \\
\text { our patience. }\end{array}$ & 3.22 & 3 & .587 \\
\hline 16 & & & The interactive approach is simple to me. & 3.53 & 4 & .544 \\
\hline 17 & & \multirow{3}{*}{$\begin{array}{l}\text { A sense of } \\
\text { serenity }\end{array}$} & concentrated after the intel & 2.94 & 3 & .659 \\
\hline 18 & & & I learn to self-control after the interaction. & 2.88 & 3 & .634 \\
\hline 19 & & & $\begin{array}{l}\text { I feel the ambiance of Zen from the visual appearance } \\
\text { of the system. }\end{array}$ & 2.82 & 3 & .697 \\
\hline 20 & \multirow{5}{*}{$\begin{array}{l}\text { Aspect of } \\
\text { result }\end{array}$} & Timelessness & The duration of the interaction process goes fast. & 3.04 & 3 & .763 \\
\hline 21 & & \multirow{4}{*}{$\begin{array}{l}\text { A sense of } \\
\text { ecstasy }\end{array}$} & The interaction process brings me much pleasure. & 3.14 & 3 & .612 \\
\hline 22 & & & I enjoy the interaction proce & 3.12 & 3 & .666 \\
\hline 23 & & & $\begin{array}{l}\text { I think that interacting through water is special and } \\
\text { interesting. }\end{array}$ & 3.43 & 3 & .500 \\
\hline 24 & & & The visual appearance of Zen-Drop is attractive to me. & 3.08 & 3 & .786 \\
\hline
\end{tabular}

* The score data of this question should be interpreted reversely because the description of the question is negative.

** S. D. = standard deviation

Table 7: The Maximum Scores of the question answers of the questionnaire surveys.

\begin{tabular}{|c|c|c|c|c|}
\hline Question & Description & Mean & Mode & S. D. \\
\hline 8 & I see brightening leaves during interaction with Zen-Drop. & 3.80 & 4 & .407 \\
\hline 9 & I hear the bell sound while interacting with the system. & 3.76 & 4 & .480 \\
\hline 11 & I notice the auditory feedback of Zen-Drop. & 3.71 & 4 & .456 \\
\hline 16 & The interactive approach is simple to me. & 3.53 & 4 & .544 \\
\hline 25 & If I have another opportunity to interact with Zen-Drop, I will be confident of \\
& doing it better. & 3.43 & 4 & .612 \\
\hline
\end{tabular}

Table 8: Computed reliability values of the opinion data of Table 6

\begin{tabular}{|c|c|c|}
\hline Reliability/validity & Aspects of questions & Computed value \\
\hline Cronbach's alpha coefficient & Condition & 0.774 \\
\cline { 2 - 3 } for reliability analysis & Feeling & 0.762 \\
\cline { 2 - 3 } & Result & 0.785 \\
\cline { 2 - 3 } & Interaction & 0.636 \\
\hline
\end{tabular}




\subsubsection{EVALUATION OF EFFECTIVENESS OF THE PROPOSED SYSTEM FROM THE VIEWPOINT OF FLOW EXPERIENCE}

One of the aims of the proposed "Zen-Drop" system is for the participant to gain the experience of flow through the evaluation of the collected answer data of the questionnaires whose questions were designed in accordance with the seven situations of the flow experiences as described previously. In this section, it is desired to investigate the effectiveness of the "Zen-Drop" system for the participant to obtain the flow experience by evaluating the collected questionnaire answer data obtained from the participants right after they completed the interactions with the system. This is done for the three aspects of condition, feeling, and result, respectively, using the data shown in Table 6 as well as more of the statistical data of the questionnaire answers to be given subsequently.

\section{About the aspect of condition}

The score percentages of the respective 4-point answers to the questions in the aspect of condition are listed in Table 9. Accordingly, about the first three questions, Question 1 through 3, designed to reflect the flow situation of "great inner clarity," it can be seen that among the 49 respondents, $93.8 \%$ understood the whole interaction process, $93.9 \%$ knew how to conduct the interaction with the system, and $89.7 \%$ knew the purpose of the system. This means that in general the users may be regarded to have reached the flow situation of "great inner clarity" in completing the interactive "Zen-Drop" process. For those questions related to the other two flow situations, "knowing that the activity is doable" and "intrinsic motivation," similar results were obtained as can be seen from Table 9, i.e., the mean score of the positive answers to each of the questions is in the range of $80 \%$ to $100 \%$, meaning that the users in general tended to have experienced the two situations.

Table 9: Percentages of the frequencies of the answers to the questions in the aspect of condition.

\begin{tabular}{|c|c|c|c|c|c|c|c|c|}
\hline No. & Situation & Question & $1^{*}$ & $2^{*}$ & $3^{*}$ & $4^{*}$ & Mean & Mode \\
\hline 1 & \multirow{3}{*}{$\begin{array}{l}\text { Greatinner } \\
\text { clarity }\end{array}$} & I understand the whole interaction process. & $2.0 \%$ & $4.1 \%$ & $67.3 \%$ & $26.5 \%$ & 3.18 & 3 \\
\hline 2 & & I know how to interact with the installation. & $0 \%$ & $6.1 \%$ & $55.1 \%$ & $38.8 \%$ & 3.33 & 3 \\
\hline 3 & & I know the purpose of the Zen-Drop system. & $0 \%$ & $10.2 \%$ & $67.3 \%$ & $22.4 \%$ & 3.12 & 3 \\
\hline 4 & \multirow{3}{*}{$\begin{array}{c}\text { Knowing the } \\
\text { activity is } \\
\text { doable }\end{array}$} & I think I could instantly operate the installation. & $0 \%$ & $18.4 \%$ & $53.1 \%$ & $28.6 \%$ & 3.10 & 3 \\
\hline 5 & & $\begin{array}{l}\text { I have not noticed the red leaves during the } \\
\text { interaction. }\end{array}$ & $30.6 \%$ & $30.6 \%$ & $14.3 \%$ & $24.5 \%$ & 2.67 & $3^{* *}$ \\
\hline 6 & & I believe I could finish the whole process. & $2.0 \%$ & $12.2 \%$ & $61.2 \%$ & $24.5 \%$ & 3.08 & 3 \\
\hline 7 & \multirow{5}{*}{$\begin{array}{l}\text { Intrinsic } \\
\text { motivation }\end{array}$} & I know that I did well during the interaction. & $2.0 \%$ & $18.4 \%$ & $57.1 \%$ & $22.4 \%$ & 3.00 & 3 \\
\hline 8 & & $\begin{array}{l}\text { I see brightening leaves during interaction with } \\
\text { Zen-Drop. }\end{array}$ & $0 \%$ & $0 \%$ & $20.4 \%$ & $79.6 \%$ & 3.80 & 4 \\
\hline 9 & & $\begin{array}{l}\text { I hear the bell sound while interacting with the } \\
\text { system. }\end{array}$ & $0 \%$ & $2.0 \%$ & $20.4 \%$ & $77.6 \%$ & 3.76 & 4 \\
\hline 10 & & $\begin{array}{l}\text { I know whether I have concentrated from the tree } \\
\text { leaf colors. }\end{array}$ & $0 \%$ & $6.1 \%$ & $55.1 \%$ & $38.8 \%$ & 3.33 & 3 \\
\hline 11 & & I notice the auditory feedback of Zen- Drop. & $0 \%$ & $0 \%$ & $28.6 \%$ & $71.4 \%$ & 3.71 & 4 \\
\hline
\end{tabular}

* The score data of this question should be interpreted reversely because the description of the question is negative.

** S. D. = standard deviation

The most noticeable question among the eleven ones of the aspect of condition listed in Table 9 is Question 10, which is about mind concentration, saying that "I can know whether I have concentrated from the tree leaf colors." It is desirable to investigate here whether or not the participant's knowledge about his/her concentration really comes from the his/her awareness of the audio-visual feedbacks from the Bodhi tree, e. g., from the his/her observation of the brightening of the tree leaves during the watering process as said in Question 8, "I see brightening leaves during interaction with Zen-Drop." For this aim, the details of the cross-reference frequencies of the answer choices of the two questions, Questions 8 and 10, are listed in Table 10 and the Pearson's chi-square test is applied to check the correlation of the two questions, i.e., to test the following null hypotheses: 
Using A New Water Sensing Device to Design A Novel Interactive Installation for Practicing Concentration to Obtain Flow Experiences

$H_{0}$ : the answer to Question 10 is not related to that to Question 8 (i.e., the participant's knowledge about whether he/she has concentrated or not does not come from his/her observation of the brightening Bodhi tree leaves).

The resulting parameter values of the test computed by use of the SPSS software package are also shown in the lower part of Table 10, where the computed probability value $p=0.019$ which is smaller than the commonlyaccepted significance level value 0.05 for rejecting the null hypothesis. Therefore, $H_{0}$ is rejected, meaning that the answer to Question 10 is related to that to Question 8, or equivalently, that the user's knowledge about whether or not he/she has concentrated does come from his/her observation of the brightening Bodhi tree leaves.

Table 10: The crosstabulation of the frequency data and results of Pearson's chi-square test of the relation between concentration and the visual feedback of "Zen-Drop."

\begin{tabular}{|c|c|c|c|c|c|}
\hline & & \multicolumn{4}{|c|}{$\begin{array}{c}\text { Question 10: } \\
\text { I can know whether I have concentrated from the tree } \\
\text { leaf colors }\end{array}$} \\
\hline & & Disagree & Agree & Strongly agree & Total \\
\hline \multirow{3}{*}{$\begin{array}{l}\text { Question 8: } \\
\text { I see brightening leaves during } \\
\text { interaction with "Zen-Drop." }\end{array}$} & Agree & 1 & 9 & 0 & 10 \\
\hline & $\begin{array}{l}\text { Extremely } \\
\text { agree }\end{array}$ & 2 & 18 & 19 & 39 \\
\hline & Total & 3 & 27 & 19 & 49 \\
\hline \multirow[t]{3}{*}{ Results of Pearson's chi-square test } & \multicolumn{2}{|c|}{$\begin{array}{c}\text { Chi-square value } \\
\chi^{2}\end{array}$} & \multicolumn{2}{|r|}{7.957} & \\
\hline & \multicolumn{2}{|c|}{$\begin{array}{l}\text { Degree of freedom } \\
d f\end{array}$} & \multicolumn{2}{|r|}{2} & \\
\hline & \multicolumn{2}{|c|}{ Probability value $p$} & \multicolumn{2}{|r|}{.019} & \\
\hline
\end{tabular}

\section{About the aspect of feeling}

The score percentages of the respective 4-point answers to the questions in the aspect of feeling are listed in Table 11, from which it can be seen that the average scores of the positive answers to each of the questions for the flow situation of "completely involved in what we are doing" are all very high, in the range of $80 \%$ to $100 \%$, meaning that in general this flow situation may be said to be achieved by the participants in the "Zen-Drop" process. However, so high average scores are not found for the three questions of the flow situation of "a sense of serenity," though still high enough in the range of $70 \%$ to $80 \%$.

A noticeable question here related to training of concentration is Question 12, "Interacting with Zen-Drop is an activity that can train our concentration." It is desirable to investigate whether or not the effectiveness expressed by the answers to this question is related to those to Question 14, "I can successfully pour water into the installation." That is, it is wanted to use the Pearson's chi-square test to check the correlation between the two questions, or equivalently, to test the following null hypotheses:

$H_{0}$ : the answer to Question 14 is not related to that to Question 12 (i.e., the user's successful water pouring into the Bodhi tree is not a result of the concentration conducted during the interaction with "Zen-Drop").

For this aim, the details of the cross-reference frequencies of the answer choices of the two questions, Questions 12 and 14, are listed in Table 12, and the Pearson's test was applied to obtain results that are also shown in the lower part of the table. It can be seen that the computed probability for the null hypothesis to be true is $p=0.040$ which is smaller than the significance level 0.05; therefore, the null hypothesis is rejected, meaning that the user's successful water pouring into the Bodhi tree is indeed a result of the concentration conducted by the user during his/her interaction with the "Zen-Drop" system. Other similar tests between pairs of the questions in this aspect of feeling have also been conducted to reach similar conclusions, saying that there is a strong correlation between the user's 
successful interaction process and their capability of self-control (concentration, patience, etc.). This in turn implies that the proposed "Zen-Drop" system is effective for self-training of mind control to obtain the flow experience.

Table 11: Percentages of the frequencies of the 4-point scales of questions in the aspect of condition.

\begin{tabular}{|c|c|c|c|c|c|c|c|c|}
\hline No. & Situation & Question & 1 & 2 & 3 & 4 & Mean & Mode \\
\hline 12 & \multirow{5}{*}{$\begin{array}{c}\text { Completely } \\
\text { involved in } \\
\text { what we are } \\
\text { doing }\end{array}$} & $\begin{array}{l}\text { Interacting with "Zen-Drop" is an activity that can } \\
\text { train our concentration. }\end{array}$ & $0 \%$ & $8.2 \%$ & $63.3 \%$ & $28.6 \%$ & 3.20 & 3 \\
\hline 13 & & $\begin{array}{l}\text { I can easily control the water volume while } \\
\text { watering the installation. }\end{array}$ & $0 \%$ & $18.4 \%$ & $55.1 \%$ & $26.5 \%$ & 3.08 & 3 \\
\hline 14 & & I can successfully pour water into the installation. & $0 \%$ & $6.1 \%$ & $55.1 \%$ & $38.8 \%$ & 3.33 & 3 \\
\hline 15 & & $\begin{array}{l}\text { Interacting with "Zen-Drop" is an activity that can } \\
\text { train our patience. }\end{array}$ & $0 \%$ & $8.2 \%$ & $61.2 \%$ & $30.6 \%$ & 3.22 & 3 \\
\hline 16 & & The interactive approach is simple to me. & $0 \%$ & $2.0 \%$ & $42.9 \%$ & $55.1 \%$ & 3.53 & 4 \\
\hline 17 & \multirow{3}{*}{$\begin{array}{c}\text { A sense of } \\
\text { serenity }\end{array}$} & $\begin{array}{l}\text { I learn to be more concentrated after the } \\
\text { interaction. }\end{array}$ & $0 \%$ & $24.5 \%$ & $57.1 \%$ & $18.4 \%$ & 2.94 & 3 \\
\hline 18 & & I learn to self-control after the interaction. & $4.1 \%$ & $14.3 \%$ & $71.4 \%$ & $10.2 \%$ & 2.88 & 3 \\
\hline 19 & & $\begin{array}{l}\text { I feel the ambiance of Zen from the visual } \\
\text { appearance of the system. }\end{array}$ & $6.1 \%$ & $16.3 \%$ & $67.3 \%$ & $10.2 \%$ & 2.82 & 3 \\
\hline
\end{tabular}

Table 12: The crosstabulation of the frequency data and results of Pearson's chi-square test of the relation between concentration and self-control in watering "Zen-Drop."

\begin{tabular}{|c|c|c|c|c|c|}
\hline & & \multicolumn{4}{|c|}{$\begin{array}{c}\text { Question 14: } \\
\text { I can successfully pour water into the installation }\end{array}$} \\
\hline & & Disagree & Agree & $\begin{array}{l}\text { Strongly } \\
\text { agree }\end{array}$ & Total \\
\hline \multirow{4}{*}{$\begin{array}{l}\text { Question 12: Interacting with } \\
\text { Zen-Drop is an activity that can train } \\
\text { concentration }\end{array}$} & Disagree & 0 & 1 & 3 & 4 \\
\hline & Agree & 3 & 21 & 7 & 31 \\
\hline & $\begin{array}{l}\text { Strongly } \\
\text { agree }\end{array}$ & 0 & 5 & 9 & 14 \\
\hline & Total & 3 & 27 & 19 & 49 \\
\hline \multirow{3}{*}{$\begin{array}{c}\text { Results of Pearson's chi-square } \\
\text { test }\end{array}$} & \multicolumn{2}{|c|}{ Chi-square value $\chi^{2}$} & \multicolumn{3}{|c|}{10.054} \\
\hline & \multicolumn{2}{|c|}{ Degree of freedom $d f$} & \multicolumn{3}{|c|}{4} \\
\hline & \multicolumn{2}{|c|}{ Probability value $p$} & \multicolumn{3}{|c|}{.040} \\
\hline
\end{tabular}

\section{About the aspect of result}

As shown in Table 13, for almost all the questions in this aspect, the percentages of the answer choices of "agree" and "strongly agree" are larger than 80\%, indicating that the users tended to have experienced the flow situations in this aspect, namely, the senses of timelessness and ecstasy. Also, it is desirable to investigate the relation between the effectiveness resulting from the actions described in Questions 21 and 23: "the interaction process brings me much pleasure" and "I think that interacting through water is special and interesting," respectively; i.e., to check if it is the interaction through the water pouring action that brings pleasure to the user, as described in the two questions. This again can be accomplished by applying the Pearson's chi-square test to the following null hypothesis:

$H_{0}$ : the answer to Question 21 is not related to that to Question 23 (i.e., the user's pleasure obtained from the interaction process is not a result of the interesting watering action conducted in the "Zen-Drop" process).

Using the cross-reference frequency data shown in Table 14, the test results are can be obtained from running the SPSS software package. Accordingly, the resulting probability value is $p=0.011$ which is smaller than the 
significance level 0.05; therefore, the null hypothesis is rejected, meaning that the participant's pleasure obtained from the interaction process is indeed a result of the interesting watering process.

Other similar tests between pairs of the questions in this aspect of result have also been conducted to reach similar conclusions, saying that there is a strong correlation between the participant's feeling of pleasure and his/her senses of interestingness or enjoyableness in the interaction process. This implies in turn that the system is effective to bring the participant to get into the flow situation of ecstasy via the proposed interactive water pouring process.

Table 13: Percentages of the frequencies of the answers to the questions in the aspect of result

\begin{tabular}{|c|c|c|c|c|c|c|c|c|}
\hline No. & Situation & Question & 1 & 2 & 3 & 4 & Mean & Mode \\
\hline 20 & Timelessness & The duration of the interaction process goes fast. & $4.1 \%$ & $14.3 \%$ & $55.1 \%$ & $26.5 \%$ & 3.04 & 3 \\
\hline 21 & \multirow{5}{*}{$\begin{array}{c}\text { A sense of } \\
\text { ecstasy }\end{array}$} & $\begin{array}{l}\text { The interaction process brings me much } \\
\text { pleasure. }\end{array}$ & $0 \%$ & $12.2 \%$ & $61.2 \%$ & $26.5 \%$ & 3.14 & 3 \\
\hline 22 & & I enjoy the interaction process. & $2.0 \%$ & $10.2 \%$ & $61.2 \%$ & $26.5 \%$ & 3.12 & 3 \\
\hline 23 & & $\begin{array}{l}\text { I think that interacting through water is special } \\
\text { and interesting. }\end{array}$ & $0 \%$ & $0 \%$ & $57.1 \%$ & $42.9 \%$ & 3.43 & 3 \\
\hline 24 & & $\begin{array}{l}\text { The visual appearance of Zen-Drop is attractive } \\
\text { to me. }\end{array}$ & $2.0 \%$ & $20.4 \%$ & $44.9 \%$ & $32.7 \%$ & 3.08 & 3 \\
\hline 25 & & $\begin{array}{l}\text { If I have another opportunity to interact with } \\
\text { Zen- Drop, I will be confident of doing it better. }\end{array}$ & $0 \%$ & $6.1 \%$ & $44.9 \%$ & $49.0 \%$ & 3.43 & 4 \\
\hline
\end{tabular}

Table 14: Crosstabulation of the frequency data and results of Pearson's chi-square test of the relation between the user's feeling of pleasure and his/her sense of interestingness in the watering process.

\begin{tabular}{|c|c|c|c|c|}
\hline & & \multicolumn{3}{|c|}{$\begin{array}{l}\text { Question 23: } \\
\text { I think that interacting through water is special and } \\
\text { interesting }\end{array}$} \\
\hline & & Agree & $\begin{array}{l}\text { Strongly } \\
\text { agree }\end{array}$ & Total \\
\hline \multirow{4}{*}{$\begin{array}{l}\text { Question 21: } \\
\text { the interaction } \\
\text { process brings me } \\
\text { much pleasure }\end{array}$} & Disagree & 5 & 1 & 6 \\
\hline & Agree & 20 & 10 & 30 \\
\hline & $\begin{array}{l}\text { Strongly } \\
\text { agree }\end{array}$ & 3 & 10 & 13 \\
\hline & Total & 28 & 21 & 49 \\
\hline \multirow{3}{*}{$\begin{array}{lr}\quad \begin{array}{l}\text { Results } \\
\text { Pearson's } \\
\text { square test }\end{array} & \begin{array}{r}\text { of } \\
\text { chi- }\end{array}\end{array}$} & \multicolumn{2}{|c|}{ Chi-square value $\chi^{2}$} & \multicolumn{2}{|l|}{8.952} \\
\hline & \multicolumn{2}{|c|}{ Degree of freedom $d f$} & \multicolumn{2}{|l|}{2} \\
\hline & \multicolumn{2}{|c|}{ Probability value $p$} & \multicolumn{2}{|l|}{.011} \\
\hline
\end{tabular}

The Relationship between the interactive "Zen-Drop" process and the flow experience

A fact about flow experiences is that such experiences make the participants to change their awareness of selfconcentration and self-control, and bring enjoyment to them. From the above discussions of the results of the questionnaire surveys as well as the Pearson's chi-square tests, it is seen that in general the watering process of the proposed "Zen-Drop" system does have the effect of bringing the participant to feel pleasant or concentrated, roughly like being in the state of flow experience. In this section, a detailed analysis will be given to see how deep the participant is involved in various flow situations. Table 15 is a summary of Table 6 showing the average of the mean values of the answer scores of the questions of each flow situation. The higher the average mean value of a flow situation is, the more effective the watering process brings the user to enter that situation of flow.

In the result of the analysis shown in Table 15, the average mean value of the questions belonging to the $3^{\text {rd }}$ flow situation, "intrinsic motivation," is the highest, up to 3.52; and the questions belonging to this situation are about the participant's feeling of self-concentration as well as his/her awareness of the system's feedbacks during the interaction process. This means that the proposed system does have the effect of bringing the participant to enter a flow state with the interaction process being a reward for the participant, as depicted in the definition of this flow 
situation: "intrinsic motivation - whatever produces flow becomes its own reward" (appearing in Table 1). The 2nd and $3^{\text {rd }}$ highest average mean values, 3.27 and 3.24, come from questions designed for the $4^{\text {th }}$ situation, "completely involved in what we are doing," and the $7^{\text {th }}$ situation, "a sense of ecstasy," respectively. These high average values of the means indicate that the participants agree highly with the question contents, implying in turn that the meanings of the two flow situations, namely, deep involvement and extreme happiness, have been reached, as proved by the results of the Pearson's chi-square tests mentioned previously (see Tables 10,12, and 14). Finally, it is mentioned that the average mean values related to the remaining situations are also around 3.0, meaning that the participants' reflections to the contents of the questions belonging to these situations are also positive.

Table 15: Average mean values of the answer scores of the questions related to the respective flow situations obtained from the questionnaire surveys of the participants' opinions.

\begin{tabular}{|c|c|c|c|}
\hline No. & Situation of "flow" & Mean & Order \\
\hline 1 & Great inner clarity & 3.21 & 4 \\
\hline 2 & Knowing that the activity is doable & 2.90 & 5 \\
\hline 3 & Intrinsic motivation & 3.52 & 1 \\
\hline 4 & Completely involved in what we are doing & 3.27 & 2 \\
\hline $5 \& 6$ & A sense of serenity \& Timelessness & 2.92 & 6 \\
\hline 7 & A sense of ecstasy & 3.24 & 3 \\
\hline
\end{tabular}

As a summary of this section, it may be said in general that the proposed "Zen-Drop" system is effective to help the participants to get into the states of the flow experience presented by Csikszentmihalyi [4] as described in Table 1. Specifically, the following observations may be concluded:

1) the immediate feedbacks of "Zen-Drop" are prominent to the participant;

2) the participants can conduct self-concentration while interacting with the proposed system;

3) involving the participants in the proposed "Zen-Drop" process can bring pleasure to them.

\subsection{INTERVIEWS WITH EXPERTS}

To obtain more suggestions for improving the proposed system, open-ended interviews with experts have been conducted in the public exhibition, and the results were compared with those of the questionnaire surveys. Three experts were invited for the interviews, as introduced previously. Two shots of the situations of them participating in the Bodhi-tree watering process are shown in Figure 9.

The topics of the interviews with the experts include three aspects: feedback of the interactive scheme, degree of the participant's concentration, and usability of the interactive process. The opinions collected from the interviewed experts are summarized in the following.

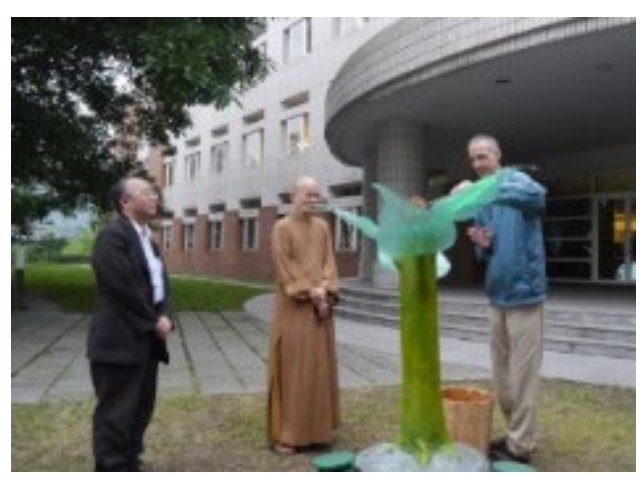

(a)

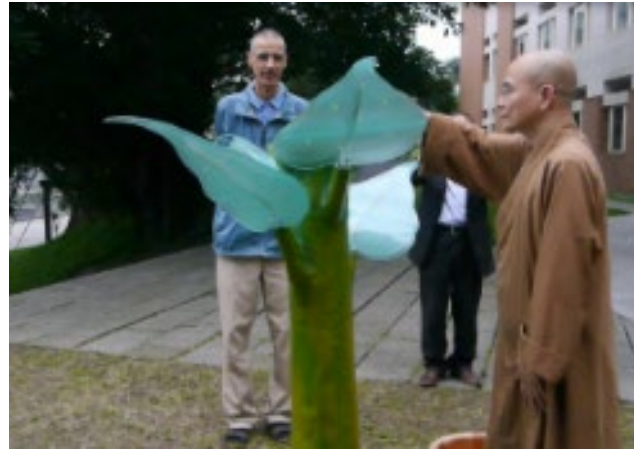

(b)

Figure 9: Two shots of the invited experts participating in the Bodhi-tree watering process before being interviewed. (a) One of the experts watering the tree. (b) Another expert watering the tree. 
The topics of the interviews with the experts include three aspects: feedback of the interactive scheme, degree of the participant's concentration, and usability of the interactive process. The opinions collected from the interviewed experts are summarized in the following.

1) About the aspect of feedback of the interactive scheme

- The audio-visual effects of the interactive installation are obvious, yielding clear feedbacks to the user.

- The green and red lighting of the Bodhi tree leaves are prominent.

- About the auditory feedback, if the issued sound for each different stage of watering is distinct, then the interactive feedback and the degree of concentration will be clearer.

2) About the aspect of degree of concentration training

- It is necessary for a user to practice concentration to a certain degree of persistency before he/she can master it in mind to increase his/her patience.

- The "Zen-Drop" installation can help adjustment of concentration and self-learning of it.

- The "Zen-Drop" system allows people and children to practice concentration and, via the interaction, to look back at themselves and control their own thoughts and attention.

3) About the aspect of usability of interaction

- The Bodhi tree is too high for the user to keep smooth interactions with the system.

- The users all know the interactive operations very well.

- The interactive operations via Bodhi tree watering are new and interesting.

\subsection{COMPARING THE RESULTS FROM QUESTIONNAIRE SURVEYS AND EXPERT INTERVIEWS}

The summaries of the opinions collected from questionnaire surveys and the open-ended expert interviews are both listed in Table 16. A detailed comparison of the two summaries can find four common views as described in the following and shown in Table 17, where the respective questions related to these four viewpoints are also listed:

1) the immediate feedbacks of the "Zen-Drop" system are obvious;

2) the respondents can adjust their self-concentration by interacting with "Zen-Drop";

3) the respondents can get into the states of flow experience during interaction; and

4) integrating water and Zen into the interactive installation is interesting to the participants.

Table 16: Comparisons between the opinions collected from questionnaire surveys and expert interviews.

\begin{tabular}{|c|c|}
\hline Summary of questionnaire surveys & Summary of expert interviews \\
\hline $\begin{array}{c}\text { The immediate feedbacks of the "Zen- } \\
\text { Drop" system are obvious. }\end{array}$ & $\begin{array}{c}\text { The audio-visual effects of the installation are } \\
\text { prominent. }\end{array}$ \\
$\begin{array}{c}\text { The participants can adjust their self- } \\
\text { concentration by interacting with the } \\
\text { "Zen-Drop" system. }\end{array}$ & $\begin{array}{c}\text { The feedback sounds for different watering stages } \\
\text { may be distinct to make the feedback and } \\
\text { concentration clearer. }\end{array}$ \\
$\begin{array}{c}\text { The participants can get into the state of } \\
\text { flow experience during the interactive } \\
\text { watering process. }\end{array}$ & $\begin{array}{c}\text { It needs to practice concentration to master it and to } \\
\text { increase patience. }\end{array}$ \\
$\begin{array}{c}\text { Integrating water and Zen into the } \\
\text { interactive installation is interesting to } \\
\text { the participants. }\end{array}$ & $\begin{array}{c}\text { The installation can help people to practice } \\
\text { concentration. }\end{array}$ \\
& $\begin{array}{c}\text { The system is too high to keep smooth interactions. } \\
\text { The interactive operations are easy to understand } \\
\text { and interesting. }\end{array}$ \\
\hline
\end{tabular}

Table 17: Conclusions of the comparison of the opinions in Table 16 with related questionnaire questions.

\begin{tabular}{|c|c|c|}
\hline Description of conclusion & $\begin{array}{l}\text { Question } \\
\text { No. }\end{array}$ & $\begin{array}{c}\text { Number of related } \\
\text { Questions }\end{array}$ \\
\hline The immediate feedbacks of the "Zen-Drop" system are obvious. & 5,7 to 11 & 6 \\
\hline $\begin{array}{l}\text { The respondents can adjust their self-concentration by interacting with } \\
\text { the "Zen-Drop" system. }\end{array}$ & 4 to16 & 13 \\
\hline
\end{tabular}




\begin{tabular}{|c|c|c|}
\hline $\begin{array}{c}\text { The respondents can get into the state of flow experience during the } \\
\text { interactive watering process. }\end{array}$ & 1 to 25 & 25 \\
\hline $\begin{array}{c}\text { Integrating water and Zen into the interactive installation is interesting } \\
\text { to the participants. }\end{array}$ & 23 & 1 \\
\hline
\end{tabular}

\section{CONCLUSIONS}

In this study, the researcher implements an interactive system "Zen-Drop" by combining the use of water and the concept of Zen into the design the system. After a public exhibition, the researcher of this study assesses the users' opinions on the flow experience by conducting questionnaire surveys and expert interviews, from which the following conclusions are drawn.

1) The man-machine interaction offered by the proposed system is innovative and interesting

Having reviewed some cases of interactive installations associated with water sensors, an interactive installation, namely, the "Zen-Drop" system, has been designed by using water as the interactive medium. The participants can have a different interactive experience due to the characteristic of watering. The water sensors can be triggered to brighten the Bodhi tree leaves through water conductivity, which is innovative and interesting.

2) The immediate feedbacks of the proposed system helps the participants concentrate on their action control

With their engagement in the watering process and the feedbacks of the proposed "Zen-Drop" system, the participants can interact with the installation in an instant fashion. The immediacy of the audio-visual feedbacks of the Bodhi tree in the system can surprise them in the interactive process, increasing their motivation to concentrate on controlling the watering action to obtain more feedbacks from the system.

3) The interactive Bodhi-tree watering process allows the participant to obtain flow experiences

The research results presented previously demonstrate that the participants accepted watering as the interactive approach of the "Zen-Drop" system, and tried to focus on controlling the use of the wooden spoon during the watering process. They also agreed that successful uses of the system brought them the feeling of pleasure after the interaction. Despite that, the extent of being in the state of the flow experience is not significant since the interaction is not so much a challenge to many of the participants, as observed in this study. The difficulty of interacting with the device may be raised to increase their involvement in the flow experience.

In short, it can be concluded that via the Bodhi-tree watering process of the proposed "Zen-Drop" system, the aim of this study, namely, "designing a tangible interactive device to help a participant to practice concentration or mind control to get into the flow state which is equivalent to the ambience of Zen," may said to have been accomplished. Considering the significance of the system's feedbacks in the man-machine interaction process, future studies may be directed to utilizing more types of audio-visual feedbacks to enhance the system's effectiveness in helping mind control and concentration. Besides, efforts may also be put on using the interactive installation as an auxiliary device for helping growing children to train their patience and concentration.

\section{SOURCES OF FUNDING}

This research received no specific grant from any funding agency in the public, commercial, or not-for-profit sectors.

\section{CONFLICT OF INTEREST}

The author have declared that no competing interests exist.

\section{ACKNOWLEDGMENT}

None. 
Using A New Water Sensing Device to Design A Novel Interactive Installation for Practicing Concentration to Obtain Flow Experiences

\section{REFERENCES}

[1] H. Chen, R. T. Wigand and M. S. Nilan, "Optimal experience of web activities," Computers in Human Behavior, Vol. 15, 1999, pp. 585-608.

[2] K. T. Yit, "Dialogue between science and buddhism: the cases of buddhist meditation and science," Universitas: Monthly Review of Philosophy and Culture, Vol. 35, 2008, pp. 97-121.

[3] Y. H. Chen, "A discussion on approaching of Zenism and new media art - A case study of Taiwan contemporary art," Journal of National Taiwan College of Arts, Vol. 81, 2007, pp. 53-69.

[4] M. Csikszentmihalyi, Beyond Boredom and Anxiety. San Francisco, CA, USA: Jossey-Bass Publishers, 1975.

[5] M. Csikszentmihalyi, F. Massimini and A. D. Fave, "Flow and biocultural evolution," in Optimal Experience: Psychological Studies of Flow in Consciousness, M. Csikszentmihalyi and I. S. Csikszentmihalyi, Eds., Cambridge, UK: Cambridge University Press, 1988, pp. 60-81.

[6] M. Csikszentmihalyi, "Flow, the Secret to Happiness (TED 2004)." [Online]. Available: https://www.ted.com/talks/mihaly_csikszentmihalyi_flow_the_secret_to_happiness, Accessed on: June 20, 2018.

[7] B. H. Kantowitz and R. D. Sorkin, Human Factors: Understanding People-system Relationships. New York, NY, USA: Wiley, 1983, pp. 156-159.

[8] D. Fallman, "The interaction design research triangle of design practice, design studies, and design exploration," Design Issues, Vol. 24, 2008, pp. 4-18.

[9] Interactive Productline IP. "Mindball Game (2003)." [Online]. Available: https://www.mindballplay.com/mindball-game/, Accessed on: Aug. 16, 2019.

[10] Industrial Technology Research Institute. "Flow of Qi (2007)," [Online]. Available: https://www.youtube.com/watch?time_continue=289\&v=EvEDkOGjoTQ, Accessed on: Aug. 19, 2019.

[11] Ventura California. "So-Cal NewsTubular Zen (2008)." [Online]. Available: https://www.youtube.com/watch?v=Hg6RnqhF6oE, Accessed on: Aug. 19, 2019.

[12] M. Yang. "Meditation Series (2012)." [Online]. Available: http://yangminha.com/?p=293\&ckattempt=3, Accessed on: Aug. 19, 2019.

[13] P. Demarinis. "Rain Dance (2001)." [Online]. Available: http://www.dac.tw/daf06/info/photo3.html, Accessed on: Feb. 20, 2019.

[14] P. Kirn. "Mocean - Water as Musical Instrument (2005)." [Online]. Available: https://cdm.link/2005/04/mocean-water-as-musical-instrument/, Accessed on: Feb. 20, 2019.

[15] G. Lasserre and A. met den Ancxt. "Kymapetra - The singing stones (2008)," [Online]. Available: http://www.scenocosme.com/kimapetra_en.htm, Accessed on Aug. 16, 2019.

[16] E. Ayaz et al. "Heart Wave (2012)." [Online]. Available: http://cargocollective.com/critmash/Heart-Wave, Accessed on: Aug. 16, 2019.

[17] M. Richardson. "Digidrench (2011)." [Online]. Available: https://vimeo.com/31521122, Accessed on: Aug. 16, 2019.

[18] A. L. Eliason, Systems Development: Analysis, Design, and Implementation. Glenview, IL, USA: Scott, Foresman \& Co., 1987.

[19] I. E. Allen and C. A. Seaman, "Likert scales and data analyses," Quality Progress, Vol. 40, 2007, pp. 64-65.

[20] J. C. Nunnally, Psychometric Theory, 2nd ed. New York, NY, USA: McGraw-Hill, 1978.

[21] L. J. Cronbach, "Coefficient alpha and the internal structure of tests," Psychometrika, Vol. 16, 1951, pp. 297334.

[22] K. S. Taber, "The use of Cronbach's Alpha when developing and reporting research instruments in science education," Research in Science Education, Vol. 48, 2018, pp. 1273-1296. 